\title{
Lipoprotein A in Diabetic Retinopathy
}

\author{
Tamphasana Wairokpam ${ }^{1}$, K.Sorojini Devi ${ }^{2}$ \\ ${ }^{1}$ Senior Resident, Department Of Medicine, RIMS, Imphal, India \\ ${ }^{2}$ Assistant Professor Of Ophthalmology Department, JNIMS, Porompat, Imphal, India
}

\begin{abstract}
Background: Type-2 diabetes mellitus is an increasingly common metabolic abnormality associated with microvascular and macrovascular complications, one of which is diabetic retinopathy which is the most common cause of visual loss in adults in the developed countries. Atherogenic lipoproteins such as total cholesterol, LDL cholesterol, oxidized low density lipoprotein, and triglycerides are associated with progression of retinopathy.
\end{abstract}

Aim: To evaluate the relationship between lipoprotein A, $L p(a)$ and retinopathy in patients with type 2 diabetes mellitus.

Material and Methods: 100 diabetic patients were enrolled in the study. Presence of retinopathy were evaluated. Serum lipid profile including Lp(a) level was assessed.

Results: High Lp(a) levels have been observed in patients with diabetic retinopathy as compared to those without retinopathy.

Conclusion: Lp(a) levels are increased in a significant percentage of patients with retinopathy compared to diabetic patients without retinopathy. The impact of $L p(a)$ levels on diabetic retinopathy needs to be further investigated.

Keywords: Lp(a), Diabetic retinopathy, Microvascular, Macrovascular, Triglycerides, Dyslipidemia .

\section{Introduction}

Diabetic retinopathy(DR) is the leading cause of vision loss in developed countries.[1] The prevalence rates of DR ranged from $7 \%$ to $12 \%$. Kempen et al reported that approximately 4.1 million US adults 40 years and older have diabetic retinopathy.[2] Diabetic retinopathy is characterized by progressive loss of vision and a high incidence of other diabetic related morbidity and mortality. The pathophysiology of DR is not completely understood but various biochemical pathways have been implicated, including polyol accumulation (via the enzyme aldose reductase), accumulation of advanced glycation end products, formation of reactive oxygen species and activation of protein kinase $\mathrm{C}$ (PKC).[5,6] It has been demonstrated that atherogenic lipoproteins such as total cholesterol, LDL cholesterol, oxidized low density lipoprotein and triglycerides are associated with progression of retinopathy, proliferative retinopathy and the development of macular oedema.[7-9] Hyperglycemia, hypertension and hypercholesterolemia are the most significant risk factors for the development and progression of diabetic retinopathy.(3,4) Nevertheless, in type 2 diabetic patients with proteinuria, delaying the progression to proliferative diabetic retinopathy remains an elusive goal in clinical setting. Therefore, it is still important to explore other risk factors with possible therapeutic applications in these patients. So, the present study was undertaken to assess the role of lipoprotein (a) as a risk factor in diabetic retinopathy and to prove the levels of $\mathrm{Lp}(\mathrm{a})$ was higher in patients with diabetic retinopathy than those without retinopathy.

\section{Material And Methods}

Source of Data: The study is a prospective observational study conducted at tertiary care teaching hospital, Imphal for a period of eight months from May 2016 to December 2016 in patients attending the Hospital. The study population comprised of 100 diabetic patients out of which 50 patients had retinopathy changes and 50 patients without retinopathy.

Inclusion criteria : Patients diagnosed as type 2 diabetes based on American Diabetic Association criteria for more than 5 years were included in the study.

Exclusion criteria : Patients with diabetes less than 5 years duration, those with chronic liver disease, hypothyroidism, end stage renal disease(non diabetic), pregnant women, gout and patients taking alcohol and drugs affecting $\mathrm{Lp}$ (a) levels like niacin, neomycin, oestrogen, hormone replacement therapy, corticosteroids were excluded from this study.

Statistical Analysis : In the present study both the cases and controls were randomly selected. Then the two groups were matched with respect to age and sex. No specific age group was selected. The Statistical software namely SPSS 11.0 and Systat 8.0 were used for the analysis of the data, and Microsoft word and Excel have been used to generate graphs, tables etc. 
Study Design: A prospective observational study consisting of 100 Type-2 Diabetes Mellitus of which 50 subjects with retinopathy and 50 subjects without retinopathy selected from hospitals attached to tertiary hospital is undertaken to investigate the levels of Lipoprotein (a).

Methods : All patients were screened for diabetes mellitus according to ADA criteria and presence of diabetic retinopathy were evaluated with direct and indirect ophthalmoscopy and fundus photography using Zeiss digital fundus camera and slit lamp biomicroscopy using 90D lens after full mydriasis. Proper history and consent of the patient were taken prior to the study. Detailed ocular examination, best corrected visual acuity and complete anterior segment examination were done in all patients. All biochemical assays were carried out with Automated Random access clinical chemistry analyzer ERBA XL-600 with ERBA TEST REAGENT. The lipid profile, urea, creatinine, liver function tests were measured. Fasting blood sugar was measured after 8-10 hours of overnight fast. Postprandial blood glucose was measured 2 hours after an oral load of $75 \mathrm{~g}$ glucose, as recommended by WHO for glucose tolerance test. The separated lipoproteins are stained with a lipid specific Sudan black stain. The excess of stain is removed with an alcoholic solution. The resulting electrophoregrams were evaluated visually for pattern abnormalities or by densitometry to obtain relative quantification of individual zones.

\section{Results}

In the present study we demonstrated that shorter the duration of type-2 Diabetes Mellitus(DM) lesser is the chance of developing retinopathy. As the duration of type-2 diabetes increased development of retinopathy increased. Incidence of Diabetic retinopathy is significantly more in patients with duration $>10$ years of $\mathrm{DM}$ with $\mathrm{P}=0.000$. In our study, the majority of patients with diabetic retinopathy are with the duration of 11 to 15 years of type $2 \mathrm{DM}$ (Table 1, Fig.1) We also analyzed the lipid parameters of the patient involved and it showed that all the parameters were abnormally elevated in the retinopathy group as compared to controls, except HDL values which were decreased in both the groups but more in the diabetic retinopathy subjects (Table 2A,2B, Fig.2a). In Diabetic retinopathy patients, Mean value of $\mathrm{Lp}$ (a) was $11.4 \mathrm{mg} / \mathrm{dl}$ as compared to patients without retinopathy where Mean value of $\mathrm{Lp}$ (a) was $5.77 \mathrm{mg} / \mathrm{dl}$ indicating that $\mathrm{Lp}$ (a) is significantly elevated in patients with Diabetic retinopathy $(\mathrm{P}<0.000)$ (Table 2A, Fig.2b).

In the present study, poor control and duration of diabetes more than 10 years are significantly associated with abnormal elevation of Lp (a) levels.

Table 1. Association of duration of DM with diabetic retinopathy

\begin{tabular}{|l|c|c|c|c|}
\hline \multirow{2}{*}{ Duration of DM } & \multicolumn{2}{|c|}{ Diabetic Retinopathy } & \multirow{2}{*}{$\begin{array}{c}\text { Total } \\
(\mathbf{N}=100)\end{array}$} & \multirow{2}{*}{ p - value } \\
\cline { 2 - 3 } & Absent $(\mathbf{N}=\mathbf{5 0})$ & Present $\mathbf{( N = 5 0 )}$ & & \\
\hline 5 - 10 years & $34(68.0 \%)$ & $13(26.0 \%)$ & $47(47.0 \%)$ & \multirow{2}{*}{$0.000 * *$} \\
\hline 11 - 15 years & $14(28.0 \%)$ & $31(62.0 \%)$ & $45(45.0 \%)$ & \\
\hline 16 - 20 years & $2(4.0 \%)$ & $6(12.0 \%)$ & $8(8.0 \%)$ & \\
\hline
\end{tabular}

** Significant at 0.01 level

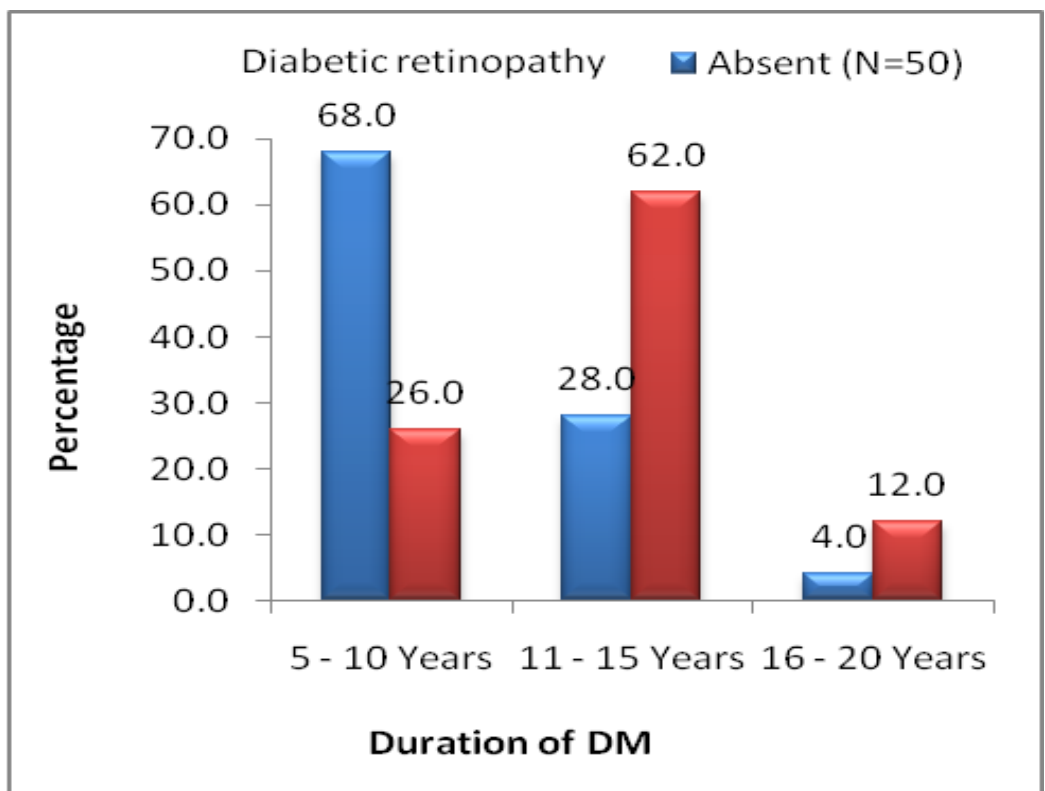

Fig 1. Association of duration of DM with diabetic retinopathy

Table 2A. Association of lipid parameters with diabetic retinopathy 


\begin{tabular}{|l|c|c|c|c|}
\hline \multirow{2}{*}{ Lipid Parameters } & \multicolumn{2}{|c|}{$\begin{array}{c}\text { Total } \\
\text { Diabetic Retinopathy }\end{array}$} & p - value \\
\cline { 2 - 3 } & $\begin{array}{c}\text { Absent } \\
(\mathbf{N = 5 0})\end{array}$ & $\begin{array}{c}\text { Present } \\
(\mathbf{N = 5 0})\end{array}$ & \\
\hline TC (> 200 mg/dl) & $0(0.0 \%)$ & $36(72.0 \%)$ & $\begin{array}{c}36 \\
(36.0 \%)\end{array}$ & $0.000^{* *}$ \\
\hline LDL (> 130 mg/dl) & $25(50.0 \%)$ & $43(86.0 \%)$ & $\begin{array}{c}68 \\
(68.0 \%)\end{array}$ & $6.143(0.000)^{* *}$ \\
\hline HDL (< 35 mg/dl) & $33(66.0 \%)$ & $26(52.0 \%)$ & $\begin{array}{c}59 \\
(59.0 \%)\end{array}$ & $1.904(0.120)^{\mathrm{NS}}$ \\
\hline TGL (> 150 mg/dl) & $38(76.0 \%)$ & $50(100.0 \%)$ & $\begin{array}{c}88 \\
(88.0 \%)\end{array}$ & $0.000^{* *}$ \\
\hline $\begin{array}{l}\text { Lipoprotien } \\
(<\mathbf{1 0} \mathbf{~ m g / d l )}\end{array}$ & $50(100.0 \%)$ & $3(6.0 \%)$ & $\begin{array}{c}53 \\
(53.0 \%)\end{array}$ & $0.000^{* *}$ \\
\cline { 1 - 3 } $\begin{array}{c}\text { Lipoprotein } \\
(>\mathbf{1 0} \mathbf{~ m g / d l )}\end{array}$ & $0(0.0 \%)$ & $47(94.0 \%)$ & $\begin{array}{c}47 \\
(47.0 \%)\end{array}$ & \\
\hline
\end{tabular}

** Significant at 0.01 level NS $\rightarrow$ Not Significant

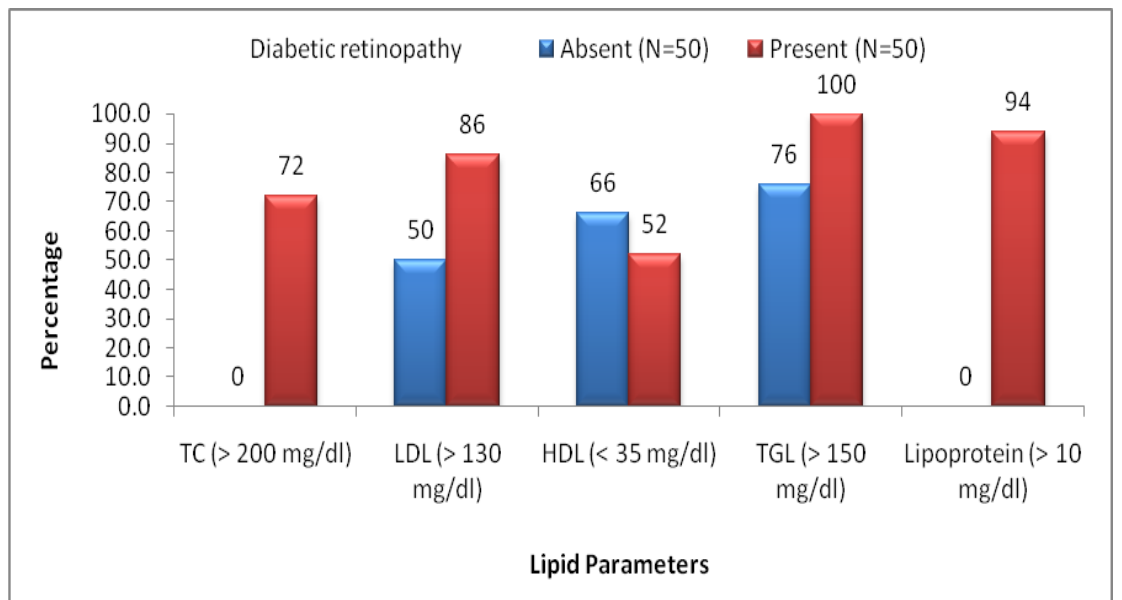

Fig 2a. Association of lipoprotein with diabetic retinopathy

Table 2B. Comparison of lipid parameters

\begin{tabular}{|l|l|l|l|l|}
\hline \multirow{2}{*}{ Lipid Parameters } & \multicolumn{2}{|c|}{ Diabetic Retinopathy } & \multirow{2}{*}{ Total $(\mathbf{N}=\mathbf{1 0 0})$} & \multirow{2}{*}{ p - value } \\
\cline { 2 - 3 } & Absent $(\mathbf{N}=\mathbf{5 0})$ & Present $(\mathbf{N}=\mathbf{5 0})$ & & \\
\hline Total Cholesterol & $170 \pm 11.0$ & $205 \pm 20.8$ & $187 \pm 24.1$ & $0.000^{* *}$ \\
\hline LDL Cholesterol & $127 \pm 8.09$ & $148 \pm 15.4$ & $137 \pm 16.1$ & $0.000^{* *}$ \\
\hline HDL Cholesterol & $33.8 \pm 2.77$ & $34.8 \pm 2.93$ & $34.3 \pm 2.88$ & $0.111^{\text {NS }}$ \\
\hline Triglycerides & $178 \pm 31.7$ & $255 \pm 30.7$ & $216 \pm 49.7$ & $0.000^{* *}$ \\
\hline Lipoprotein & $5.77 \pm 0.72$ & $11.4 \pm 0.79$ & $8.40 \pm 2.75$ & $0.000^{* *}$ \\
\hline
\end{tabular}

** Significant at 0.01 level NS $\rightarrow$ Not Significant

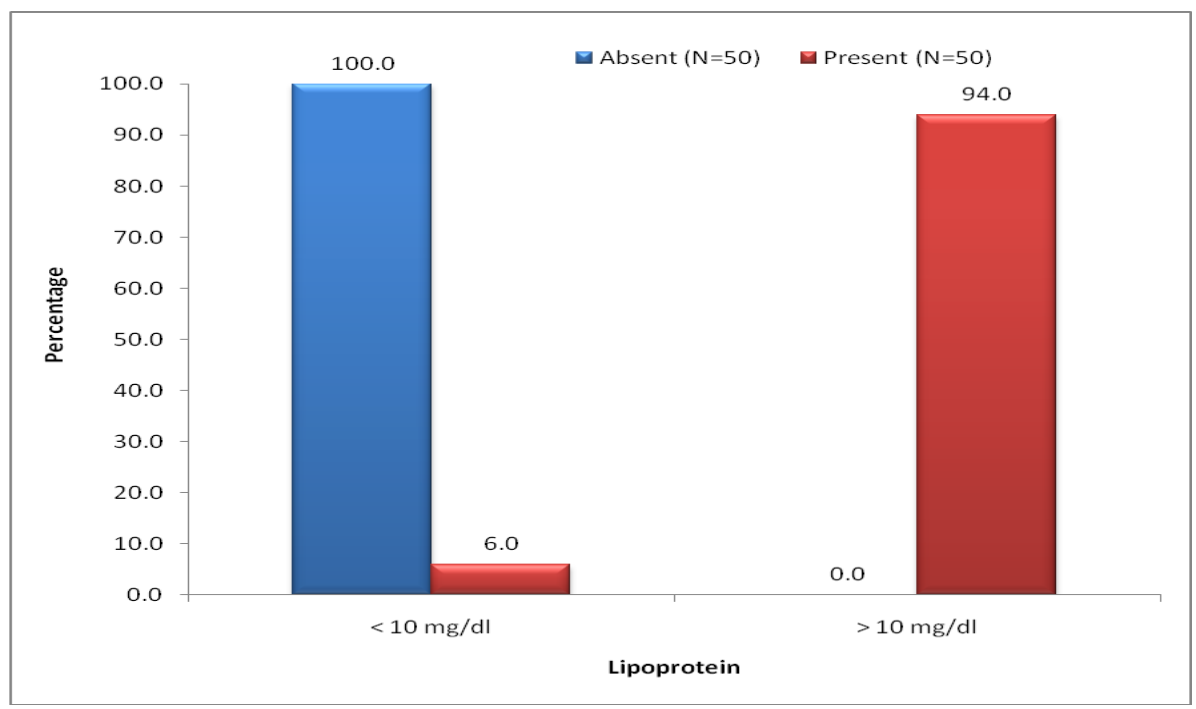

Fig 2b. Association of lipoprotein with diabetic retinopathy 


\section{Discussion}

Type-2 diabetes mellitus is a metabolic disorder affecting carbohydrate, fat and protein metabolism. An estimated 50\% of all diabetic patients, either type 1 or type 2 are dyslipidemic.[7] Dyslipdemia is observed in patients with diabetic retinopathy significantly when compared to those without retinopathy, and in those who has long term diabetes more than 10 years and in whom the glycemic control was poor.[20,21,23-25] Type 2 diabetes with retinopathy is associated with several lipid abnormalities including hypertriglyceridemia, reduced HDL level, an increased proportion of small, dense LDL particles and elevated Lp(a).[24,26] In our study, Lp(a) level is significantly elevated in patients with diabetic retinopathy which is consistent with the finding of Malaguarnera G et al [21], Yun JS et al[28] and Gaonkar B et al[29]. Many risk factors like the duration of diabetes, degree of glycemic control and age of the patient are identified in the causation of the diabetic microvascular complications. Abnormal plasma lipoprotein profiles contribute to the increased risk in CAD and diabetic retinopathy.

Berg K. detected Lp(a) in 1963 in Norway.[13] Lp (a) is assembled from two different components. One is an LDL and contains all the lipid with hydrophobic apo B-100; other is a hydrophilic glycoprotein apo (a). Both LDL and apo (a) are believed to be linked by a single disulphide bond.[10-12,18,19] A breakthrough in Lp (a) research was the cloning and sequencing of Apo (a) by Mc Lean et al[10], which revealed a high degree of homology of Apo (a) with plasminogen and that their genes are adjacent on chromosome $[11,12,18,19]$. Plasminogen is a plasma serine protease of the fibrinolytic system. Although the normal function of Lp (a) is unknown, the close homology between Lp (a) and plasminogen has raised the possibility that this lipoprotein may inhibit endogenous fibrinolysis by competing with plasminogen for binding on the endothelial surface.[11,16,17,19] Apo (a) may also induce monocyte chemotactic activity in the vascular endothelium.[16,17,19] This mechanism may contribute to a role of $\mathrm{Lp}$ (a) in atherothrombosis which may have a significant role in the development of diabetic retinopathy.[16,17,19,27] However, there are few and conflicting studies examining the relationship between lipoprotein(a) and retinopathy in patients with type 2 diabetes mellitus.

\section{Conclusion}

Hence, we conclude that serum dyslipidemia is much more common in type-2 diabetes with retinopathy compared to those without retinopathy. Poor control of Diabetes Mellitus is the lone significant predictor of elevated Lipoprotein (a) followed by duration of Diabetic $>10$ years. Lp (a) values are significantly elevated in Diabetic retinopathy. Thus, it is essential to include $\mathrm{Lp}(\mathrm{a})$ in a battery of tests for evaluation of macro and microvascular complications in type 2 diabetes.

\section{References}

[1]. Zheng Y, He M, Congdon N. The Worldwide epidemic of diabetic retinopathy. Indian Journal of Ophthalmology, 60(5), Sept.-Oct. 2012, 428-431.

[2]. Kempen JH, O'Colmain BJ, Leske MC, Haffner SM, Klein R, Moss SE et al. The prevalence of diabetic retinopathy among adults in the United States. Archives of Ophthalmology, 122(4), 2004,552-563.

[3]. Powers AC; Diabetes mellitus, In : Braunwald (ed.): Harrison's principles of internal medicine 2, $18^{\text {th }}$ edn. New York; McGraw Hill $2012 ; 2152$.

[4]. Newfield RS, Polak M, Marchase R, Czernichow P. Epidemiology and genetics of diabetic complications. Diabetologia,40(3),1997,B62-B64.

[5]. Hohman TC, Nishimura C, Robison Jr. WG. Aldose reductase and polyol in cultured pericytes of human retinal capillaries. Experimental Eye Research, 48(1),1989,55-60.

[6]. Duh E, Aiello LP. Vascular endothelial growth factor and diabetes: the agonist versus antagonist paradox. Diabetes,48(10),1999,1899-1906.

[7]. Orchard TJ. Dyslipoproteinemia and diabetes. Endocrinology and Metabolism Clinics of North America,19(2),1990,361-380.

[8]. Davis MD. Worsening of diabetic retinopathy after improvement of glycemic control. Archives of Ophthalmology,116(7),1998,931-932.

[9]. Uçgun NI, Yildirim Z, Kiliç N, Gürsel E. The importance of serum lipids in exudative diabetic macular edema in type 2 diabetic patients. Annals of the New York Academy of Sciences, 1100,2007, 213-217.

[10]. McLean JW, Tomlinson JE., Kaung WJ, Eaton DL, Chen EY, Fless GM et al. cDNA sequence of human apolipoprotein (a) is homologous to plasminogen, Nature 330, 18 Nov1987; 132-137; doi:10.1038/330132a0.

[11]. Miles LA, Fless GM, Levin EG, Scanu AM, Plow EF. A potential basis for the thrombotic risks associated with lipoprotein(a). Nature, 339(6222), 1989, 301-303.

[12]. Hajjar KA, Gavish D, Breslow JL, Nachman RL. Lipoprotein(a) modulation of endothelial cell surface fibrinolysis and its potential role in atherosclerosis. Nature, 339(6222), 1989, 303-305.

[13]. Berg K. A new serum type system in man, the LP system. Acta Patho Microbial Scand, 59, 1963,369.

[14]. Leske MC, Wu S, Hyman L, Li X, Hennis A, Connell AM, et al. Diabetic retinopathy in a black population: the Barbados eye study. Ophthalmology, 106(10),1999,1893-1899.

[15]. Friedewald WT, Levy RI, Fredrickson DS. Estimation of the concentration of low-density lipoprotein cholesterol in plasma,

[16]. without use of the preparative ultracentrifuge. Clinical Chemistry, 18(6),1972,499-502.

[17]. Schaefer EJ, Ordovas JM. Metabolism of apolipoproteins A-I, A-II and A-IV. Methods in Enzymology,129,1986,420- 443.

[18]. Ordovas JM, Peterson JP, Santaniello P, Cohn JS, Wilson PWF, Schaefer EJ. Enzyme-linked immunosorbent assay for human plasma apolipoprotein B. Journal of Lipid Research, 28(10), 1987, 1216-1224.

[19]. Lenzi S, Scanu A, De Caterina R. Lipoprotein(a) as an athero-thrombotic risk factor: epidemiological evidence and possible 
[20]. pathogenetic mechanisms. Giornale Italiano di Cardiologia, 26(10), 1996, 1203-1225.

[21]. Galvano F, Malaguarnera M, Vacante M, Motta M, Russo C, Malaguarnera G,et al. The physiopathology of lipoprotein (a).Frontiers in Bioscience,2,June2010,866- 875.

[22]. Steiner G. Dyslipoproteinemias in diabetes. Clinical \& Investigative Medicine, 18(4),1995, 282-287.

[23]. Malaguarnera G, Gagliano C, Bucolo C, Vacante M, Salomone S et al. Lipoprotien(a) serum levels in diabetic patients with retinopathy. Biomed Research International Volume 2013, Article ID 943505, 5 pages http://dx.doi.org/10.1155/2013/943505

[24]. Klein RF, Feingold KR, Morgan C, Stern WH, Siperstein MD. Relationship of muscle capillary basement membrane thickness and diabetic retinopathy. Diabetes Care, 10(2), 1987,195-199.

[25]. Rodriguez-Fontal M, Kerrison JB, Alfaro DV, Jablon EP. Metabolic control and diabetic retinopathy. Current Diabetes Reviews, 5(1),2009,3-7.

[26]. Calmarza P, Vella JC. Lipids, lipoproteins and apolipoprotein (a) isoforms in type 2 diabetic patients. Journal of Cardiovascular Risk, 6(3),1999,171-175.

[27]. Jeremy Y Yu, Lyons TJ. Modified lipoproteins in diabetic retinopathy- A local action in the retina. J Clin Exp Ophthalmol, 4(6),2013,314.

[28]. Maioli M, Tonolo G, Pacifico A, MCiccarese M, P.Brizzi P, Kohner EM et al. Raised serum apolipoprotein (a) in active diabetic retinopathy. Diabetologia,36(1),1993,88-90.

[29]. Zhang L, Chen B, Tang L. Metabolic memory: mechanisms and implications for diabetic retinopathy. Diabetes Research and

[30]. Clinical Practice, 96(3),2012,286-293.

[31]. Yun JS, Lim TS, Cha SA, Ahn YB, Song KH, Choi JA et al. Lipoprotein(a) predicts the development of diabetic retinopathy in people with type 2 diabetes mellitus. J Clin Lipidol.10(2), March-April 2016:426-33. doi: 10.1016/j.jacl.2015.12.030.

[32]. Gaonkar B, Prabhu K. Serum Levels of Lipoprotein A in Patients with Diabetic Retinopathy. International Journal Of Scientific Research, 4 (8), 2015, 639-640. ISSN 2277 - 8179 